\title{
Role of transvaginal sonography in the diagnosis of early pregnancy failure
}

\author{
Rosy Khanam*, Pranoy Nath
}

Department of Obstetrics and Gynecology, Silchar Medical College and Hospital, Cachar, Assam, India

Received: 12 December 2020

Accepted: 15 January 2021

\author{
*Correspondence: \\ Dr. Rosy Khanam, \\ E-mail: khanamrosy7@gmail.com
}

Copyright: (c) the author(s), publisher and licensee Medip Academy. This is an open-access article distributed under the terms of the Creative Commons Attribution Non-Commercial License, which permits unrestricted non-commercial use, distribution, and reproduction in any medium, provided the original work is properly cited.

\begin{abstract}
Background: The most crucial period of intra uterine life are the first twelve weeks of gestation, where history and clinical examination may often be inconclusive. Ultrasonography plays an important role in confirming the pregnancy, its site and viability. The objective of this study was to determine the first trimester ultrasonographic findings of a normal intrauterine pregnancy, early pregnancy failure and to have a comparative evaluation of transvaginal with transabdominal ultrasonography in the diagnosis of early pregnancy failure.

Methods: Cross sectional study done in the Department of Obstetrics and Gynaecology, Silchar Medical College and Hospital from $1^{\text {st }}$ June 2019 to $31^{\text {st }}$ May 2020. Data were collected from 80 patients presenting to the Antenatal and Gynaecology OPD of Silchar Medical College, with positive urine beta HCG test with signs and symptoms suggestive of early pregnancy. The study was conducted during the said study period. General physical and pelvic examination done for in the cases provisional clinical diagnosis and subjected to ultrasound. Sonography by both abdominal and transvaginal method was done and findings were compared.

Results: $70 \%$ of cases in this study came out to be of normal pregnancy while $30 \%$ of the total cases were of abnormal pregnancy. Various fetal developmental markers such as gestational sac, yolk sac, fetal pole, fetal heart motion, double decidual sac sign were visualised in better number of cases by transvaginal sonography than by abdominal. Amongst cases of abnormal pregnancy, parameters such as detection of abnormality in shape of gestational sac, abnormality in yolk sac were found to be better seen with transvaginal sonography than with transabdominal sonography. Measurements of mean sac diameter, crown rump length were found to be similar by both the methods.

Conclusions: Combination of abdominal sonography and transvaginal sonography complements the defects of two methods and thus improves the accuracy of diagnosis. Thus it can be said that transvaginal sonography should not be used as a substitute but as a conjunct with abdominal sonography for better visualization, improved diagnosis thereby leading to better management of the patients.
\end{abstract}

Keywords: Early pregnancy failure, Fetal developmental markers, Transabdominal sonography, Transvaginal sonography

\section{INTRODUCTION}

Pregnancy is a significant event in woman's life and emotional attachment to the pregnancy and fetus may develop early in the first trimester. For most women experiencing a first trimester loss is a difficult and vulnerable time and when it occurs the grief can be as profound as for any perinatal or other major loss. Early pregnancy loss- also known as fetal demise, miscarriage, or spontaneous abortion- is defined as a "nonviable, intrauterine pregnancy with either an empty gestational sac or a gestational sac containing an embryo or fetus without fetal heart activity prior to 12 weeks and 6 days of gestation". ${ }^{1}$ 
Of the known pregnancies, $8 \%$ to $20 \%$ terminate in spontaneous abortion., ${ }^{2,3}$ Approximately $80 \%$ of spontaneous pregnancy losses occur in the first trimester. ${ }^{4,5}$ The most common cause of a first trimester pregnancy loss is embryonal genetic abnormalities, which occur in more than $50 \%$ of the cases, with aneuploidy being the most frequent abnormality. ${ }^{6}$ Improvement in the identification of the sonographic landmarks of normal embryonic development and awareness of the sonographic risk factors of pregnancy failure help in more case specific management strategies. ${ }^{7}$

In this study, conducted at the Silchar Medical College and Hospital for a duration of one year, patients coming with complaints suggestive of pregnancy in the first trimester were taken into consideration and we assessed the findings obtained on transvaginal sonography and compared those findings with that obtained on transabdominal sonography.

\section{METHODS}

The study conducted was a cross sectional study in a tertiary health care centre- Silchar Medical College and Hospital. The institute is situated in Silchar town of Cachar district in the State of Assam, India.

Patients attending the Antenatal and Gynaecology OPD in Silchar Medical College and hospital during the study period of $1^{\text {st }}$ June 2019 to $31^{\text {st }}$ May 2020, with signs and symptoms suggestive of early pregnancy were taken into consideration. 80 such patients willing to participate in the study are considered, transabdominal ultrasonography is done, analysed and compared with results obtained through transvaginal ultrasonography.

The study was duly approved by the Ethical committee, Silchar Medical College and Hospital, Silchar in meeting held on $10^{\text {th }}$ January 2019.

Clinical details like age, obstetric history, medical history, past history, menstrual history and details of present pregnancy in terms of period of amenorrhoea with other associated symptoms or complaints were noted. A detailed clinical examination including general physical examination and pelvic examination was done to arrive at a provisional clinical diagnosis.

All patients were subjected firstly to transabdominal sonography and then transvaginal sonography was done.

Data was collected in a preformed proforma. Clinical and ultrasound findings were correlated. Ultrasonographic evaluation of patients was done using the following machines: Transvaginal sonography: Samsung RS80A with Prestige. Probe: E3-12A, field of view: 70 degree, (convex ultrasound transducer). Transabdominal sonography: Samsung RS80A with Prestige. Probe: CA17A, field of view: 210 degree, (endocavity ultrasound probe).

\section{Inclusion criteria}

Patients with a history of per vaginal bleeding, of any amount in the setting of amenorrhoea of up to 12 weeks or known pregnancy in the first trimester (either from a urine pregnancy detection test or $\beta$-HCG levels or from a previous ultrasound scan). Patients with positive urine pregnancy test, having shorter duration of amenorrhoea, even if not sure of their dates. Patients who give consent for participation in this study.

\section{Exclusion criteria}

Patients who decline to participate in the study. Patients with no amenorrhoea, or in whom pregnancy has been excluded by a negative urine pregnancy detection test or low serum $\beta$-HCG levels. Patients with pregnancy beyond the first trimester (greater than 12 weeks gestation). Patients with an indeterminate ultrasound scan both by TAS and TVS and would therefore require a follow up scan. Patients with any gynaecological condition.

\section{Statistical methods}

Inferential statistics- for quantitative data, Student's paired t- test was used. For qualitative data, Chi square test with Yates correction for continuity and Fischer's exact test for the $\mathrm{p}$ value was used.

All the statistical methods were carried out through Graph Pad Prism (8.4.3) Software.

\section{RESULTS}

\section{Distribution of cases according to visualisation of gestational sac}

Transvaginal sonography showed gestational sac in all the 56 patients $(100 \%)$ whereas abdominal method could show gestational sac in 51 out of the 56 cases of normal pregnancy. (91.07\%).

Table 1: Visualisation of gestational sac.

\begin{tabular}{|lll|}
\hline \multicolumn{2}{|l|}{ Normal pregnancy } \\
\hline Procedure & Visualised & Not visualised \\
\hline TAS $(\mathrm{n}=56)$ & 51 & 05 \\
\hline TVS $(\mathrm{n}=56)$ & 56 & 00 \\
\hline $\begin{array}{l}\chi^{2}, \mathrm{df}: 3.350, \\
\text { significant) }\end{array}$ & $\mathrm{z}$ value : $1.830 ; \mathrm{p}$ value: 0.0569 (not \\
\hline $\begin{array}{l}\text { Abnormal pregnancy } \\
\text { TAS ( }=24)\end{array}$ & 15 & 09 \\
\hline TVS $(\mathrm{n}=24)$ & 15 & 09 \\
\hline
\end{tabular}

In the abnormal pregnancy, there were 15 cases out of 24 $(62.5 \%)$ where gestational sac could be seen both by TAS as well as TVS, while in 9 out of 24 cases, gestational sac could not be seen as those 9 cases were of incomplete 
abortion where products of conceptus were on the way of expulsion. Although statistically not significant, transvaginal Sonography showed gestational sac in a better number of cases than transabdominal sonography in cases of normal pregnancy while in abnormal pregnancy both the methods could detect gestational sac in equal number of cases.

\section{Distribution of mean sac diameter according to gestational age}

It can be said that the mean values of mean sac diameter obtained by TVS and TAS, at various weeks from last menstrual period (LMP) were almost identical.
Distribution of cases according to the shape of gestational sac (cases where gestational sac was visualised)

In the normal pregnancy, $(n=56)$, TVS showed regular gestational sac in 56 cases, that is, $100 \%$ cases, while TAS, of the 51 cases, where it could detect gestational sac, regular gestational sac was seen in 47 cases, and irregular shape in 04 cases. It could probably be due to overdistended urinary bladder. In the abnormal pregnancy $(n=24)$, there were 09 cases of incomplete abortion where gestational sac was not visualised. Of the 15 cases where gestational sac was visualised, TVS showed abnormality in shape of gestational sac in 09 cases that is $60 \%$, while TAS showed abnormal gestational sac in 05 cases, that is, $33 \%$.

Table 2: Distribution of mean sac diameter according to gestational age.

\begin{tabular}{|lllll|}
\hline Gestational age (in weeks) & Range (in mm) Type of scan & Mean \pm SD (in mm) Type of scan \\
\hline 4-5 weeks & TAS & TVS & TAS & TVS \\
\hline 6-7 weeks & $0-8 \mathrm{~mm}$ & $6-8 \mathrm{~mm}$ & $8 \mathrm{~mm}$ & $7.5 \pm 1$ \\
\hline 8-9 weeks & $8-24 \mathrm{~mm}$ & $8-24 \mathrm{~mm}$ & $15.4 \pm 5.338$ & $15.22 \pm 5.191$ \\
\hline $\mathbf{1 0 - 1 1}$ weeks & $20-36 \mathrm{~mm}$ & $20-37 \mathrm{~mm}$ & $26.929 \pm 5.498$ & $27.357 \pm 5.956$ \\
\hline $\mathbf{1 2}$ weeks & $36-48 \mathrm{~mm}$ & $36-46 \mathrm{~mm}$ & $39.619 \pm 3.84$ & $39.381 \pm 3.866$ \\
\hline
\end{tabular}

Table 3: Distribution of cases according to shape of gestational sac.

\begin{tabular}{|c|c|c|c|c|}
\hline Type of pregnancy & Type of scan & Normal (regular shape) & Abnormal (distorted/ irregular shape) & Total \\
\hline \multirow{3}{*}{ Normal $(n=56)$} & TAS & $92.16 \%$ & $7.84 \%$ & 100 \\
\hline & TVS & $100 \%$ & 0.0 & 100 \\
\hline & $\chi^{2}=2.643 ; \mathrm{z}-\mathrm{v}$ & ue- $1.626 ; \mathrm{df}=1 ; \mathrm{p}$ value $=0$ & 484 (significant) & \\
\hline \multirow{3}{*}{ Abnormal $(n=24)$} & TAS & $66.67 \%$ & $33.33 \%$ & 100 \\
\hline & TVS & $40 \%$ & $60 \%$ & 100 \\
\hline & $\chi^{2}=1.205 ; \mathrm{df}$ & value:1.098; $\mathrm{p}$ value: 0 & 23 (not significant) & \\
\hline
\end{tabular}

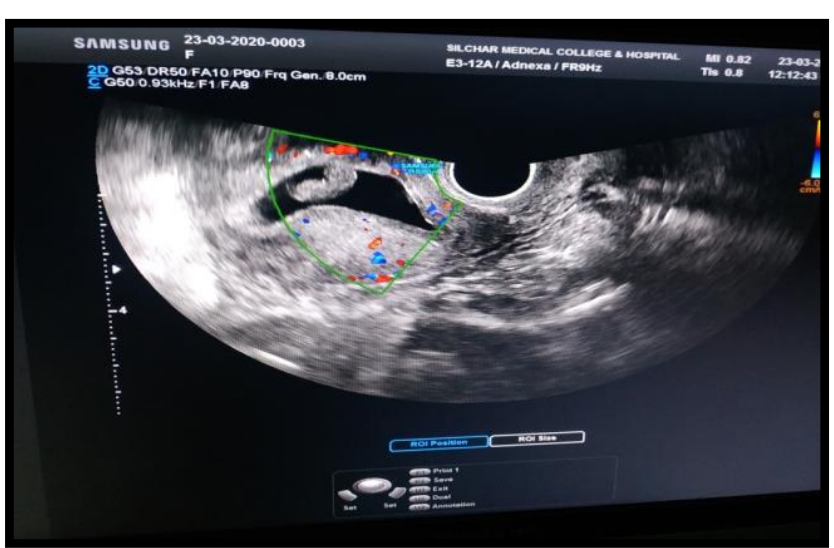

Figure 1: Deformed gestational sac with no cardiac activity and no blood flow on colour Doppler study (suggestive of early pregnancy failure) in an 8 week embryo.

\section{Distribution of cases according to visualisation of yolk sac}

Amongst cases of normal pregnancy where yolk sac was visualised by transabdominal sonography, there were 41 out of 43 cases where no abnormality was detected. In 2 out of the total 43 cases, abnormality in yolk sac was detected. Amongst cases where yolk sac was visualised by transvaginal sonography, there were 46 cases with normal yolk sac and 1 case with abnormality. In cases of abnormal pregnancy, transabdominal sonography detected 4 out of 11 cases (considering cases where yolk sac was visualised in abnormal pregnancy), that is $36.36 \%$ cases where yolk sac appeared abnormal and 7 cases of normal yolk sac constituting $63.64 \%$ cases. While transvaginal sonography detected 8 out of 11 cases, that is $72.72 \%$ cases of abnormality in yolk sac, there were 3 cases with normal yolk sac. 
Table 4: Distribution of cases according to visualisation of yolk sac.

\begin{tabular}{|c|c|c|c|c|c|c|}
\hline Type of pregnancy & Type of scan & No & & Abl & & Total \\
\hline \multirow{3}{*}{ Normal $(n=56)$} & TAS $(n=43)$ & 41 & $95.35 \%$ & 02 & $4.65 \%$ & 100 \\
\hline & TVS $(n=47)$ & 46 & $97.87 \%$ & 01 & $2.13 \%$ & 100 \\
\hline & \multicolumn{6}{|c|}{$\chi^{2}=0.006142 ; \mathrm{df}: 1 ; \mathrm{z}-$ value $=0.07837 ; \mathrm{p}$ value $=0.6043$ (not significant $)$} \\
\hline \multirow{3}{*}{ Abnormal $(n=24)$} & TAS $(n=11)$ & 07 & $63.64 \%$ & 04 & $36.36 \%$ & 100 \\
\hline & TVS $(n=11)$ & 03 & $27.27 \%$ & 08 & $72.73 \%$ & 100 \\
\hline & \multicolumn{6}{|c|}{$\chi^{2}=1.650 ;$ df: $1 ; \mathrm{z}-$ value $=1.285 ; \mathrm{p}$ value $=0.1984$ (not significant) } \\
\hline
\end{tabular}

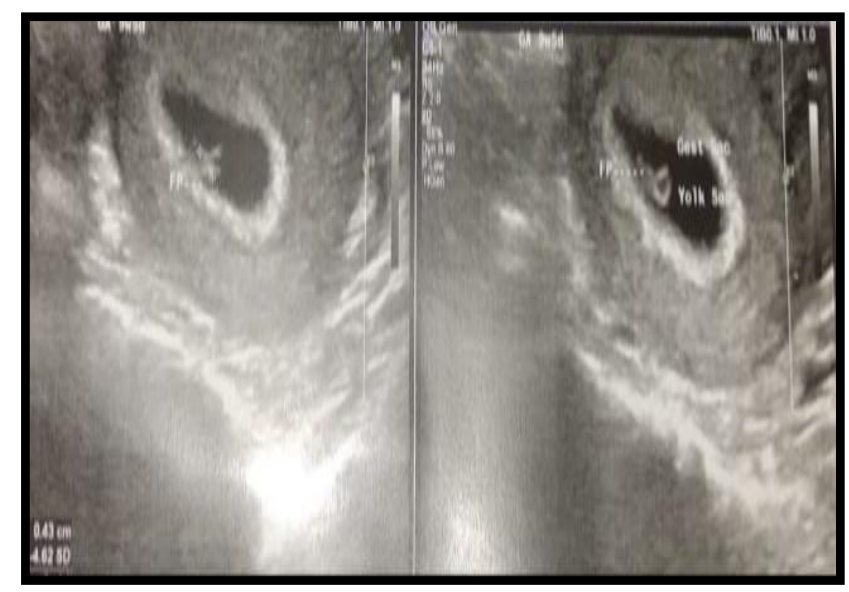

Figure 2: Gestational sac, yolk sac and fetal pole as visualised by transabdominal sonography (left) and transvaginal sonography (right).

\section{Distribution of cases according to visualisation of double decidual sac sign}

Double decidual sac sign (DDSS) was looked for to confirm early intrauterine pregnancy in cases where yolk sac or fetal pole had not developed. We looked for sac sign in all cases where yolk sac was not visible either in TAS or TVS.

In cases of normal pregnancy, transabdominal sonography detected 6 cases with sac sign, i.e. $46.15 \%$ whereas with transvaginal sonography, 12 cases were visible, that is $92.31 \%$ of the cases and the difference was found to be significant with $p$ value: 0.0302 . In cases of abnormal pregnancy, findings were same for both transabdominal and transvaginal sonography, i.e. both could detect DDSS in 3 cases.

Table 5: Distribution of cases according to visualisation of double decidual sac sign.

\begin{tabular}{|llllllll|}
\hline Type of pregnancy & Type of scan & Seen & \multicolumn{4}{c|}{ Not seen } \\
\hline \multirow{3}{*}{ Normal $(\mathbf{n}=\mathbf{1 3})$} & TAS $(\mathrm{n}=13)$ & 06 & $46.15 \%$ & 07 & $53.84 \%$ & 100 \\
\cline { 2 - 7 } & TVS $(\mathrm{n}=13)$ & 12 & $92.31 \%$ & 01 & $7.69 \%$ & 100 \\
\cline { 2 - 7 } & $\chi^{2}=4.514 ; \mathrm{df}: 1 ; \mathrm{z}$ value=2.125; p value $=0.0302$ & (significant) \\
\hline \multirow{2}{*}{ Abnormal $(\mathbf{n = 4})$} & TAS $(\mathrm{n}=4)$ & 03 & $75 \%$ & 01 & $25 \%$ & 100 \\
\cline { 2 - 7 } & TVS $(\mathrm{n}=4)$ & 03 & $75 \%$ & 01 & $25 \%$ & 100 \\
\hline
\end{tabular}

\section{Distribution of cases according to visualisation of fetal pole and fetal heart motion}

We looked for fetal pole in cases where yolk sac was present. Yolk sac was seen in 43 cases of normal pregnancy by abdominal sonography, amongst those 43 cases, fetal pole was seen in 40 cases that is $93.02 \%$ of the cases. While with transvaginal sonography we were able to see 47 cases with fetal pole. Of those 47 , yolk sac was seen in 45 cases that is $95.74 \%$ of the cases. In abnormal pregnancies where we could visualise the yolk sac, fetal pole could be seen in 10 out of 11 cases both by transabdominal (TAS) and transvaginal sonography (TVS), i.e. $90.91 \%$ of the cases, and not seen in 1 case.

In cases where we could visualise the fetal pole $(n=40$ for TAS, $n=45$ for TVS, in cases of normal pregnancy), we looked for the fetal heart motion. In normal pregnancies where fetal pole was seen, on doing TAS we found 35 cases where fetal heart motion could also be seen, i.e., $87.5 \%$ of the cases, however, in 5 cases we could not detect fetal heart motion. On TVS, there were 42 cases $(93.33 \%)$, where we could detect the fetal heart motion, however in 3 cases, fetal heart motion could not be detected. 
Table 6: Distribution of cases according to visualisation of fetal pole and fetal heart motion.

\begin{tabular}{|c|c|c|c|c|c|c|}
\hline \multirow{2}{*}{ Type of pregnancy } & Type of scan & Set & & \multicolumn{2}{|c|}{ Not seen } & Total \\
\hline & \multicolumn{6}{|l|}{ Fetal pole } \\
\hline \multirow{3}{*}{ Normal } & TAS $(n=43)$ & 40 & $93.02 \%$ & 03 & $6.97 \%$ & 100 \\
\hline & TVS (n=47) & 45 & $95.74 \%$ & 02 & $4.255 \%$ & 100 \\
\hline & \multicolumn{6}{|c|}{$\chi^{2}=0.01048 ; \mathrm{df}: 1 ; \mathrm{z}$ value $=0.1024 ; \mathrm{p}$ value $=0.6668$ (not significant $)$} \\
\hline \multirow{2}{*}{ Abnormal } & TAS $(n=11)$ & 10 & $90.9 \%$ & 01 & $90.9 \%$ & 100 \\
\hline & TVS $(n=11)$ & 10 & $10 \%$ & 01 & $10 \%$ & 100 \\
\hline \multirow{3}{*}{ Normal } & \multicolumn{6}{|c|}{ Fetal heart motion } \\
\hline & TAS $(n=40)$ & 35 & $87.5 \%$ & 05 & $12.5 \%$ & 100 \\
\hline & TVS (n=45) & 42 & $93.33 \%$ & 03 & $6.67 \%$ & 100 \\
\hline \multicolumn{7}{|c|}{$\chi^{2}=0.2995 ; \mathrm{df}: 1 ; \mathrm{z}$ value $=0.5472 ; \mathrm{p}$ value $=0.4662$ (non significant $)$} \\
\hline \multirow{2}{*}{ Abnormal } & TAS $(n=10)$ & 05 & $50 \%$ & 05 & $50 \%$ & 100 \\
\hline & $\operatorname{TVS}(\mathrm{n}=10)$ & 05 & $50 \%$ & 05 & $50 \%$ & 100 \\
\hline
\end{tabular}

Table 7: Distribution of crown rump length according to gestational age.

\begin{tabular}{|lllll|}
\hline $\begin{array}{l}\text { Gestational age ( in } \\
\text { weeks) }\end{array}$ & \multicolumn{2}{l}{ Range (in mm) } & Type of scan & \multicolumn{2}{l|}{ Mean \pm SD (in mm) Type of scan } \\
& TAS & TVS & TAS & TVS \\
\hline 4-5 weeks & - & - & - & - \\
\hline 6-7 weeks & $8-9 \mathrm{~mm}$ & $6-10 \mathrm{~mm}$ & $8.5 \pm 0.7 \mathrm{~mm}$ & $8.75 \pm 1.893$ \\
\hline 8-9 weeks & $10-24 \mathrm{~mm}$ & $6-24 \mathrm{~mm}$ & $16.765 \pm 4.724 \mathrm{~mm}$ & $16 \pm 5.016 \mathrm{~mm}$ \\
\hline $\mathbf{1 0 - 1 1}$ weeks & $26-55 \mathrm{~mm}$ & $30-55 \mathrm{~mm}$ & $38.727 \pm 7.304$ & $38.727 \pm 7.535$ \\
\hline $\mathbf{1 2}$ weeks & $68-75 \mathrm{~mm}$ & $58-78 \mathrm{~mm}$ & $71.167 \pm 5.742$ & $70.837 \pm 6.882$ \\
\hline
\end{tabular}

\section{Distribution of crown rump length according to gestational age}

The length of the embryo is measured from the head (crown) to the buttocks (rump), hence the term crownrump length (CRL) which is more accurate in the first trimester. There was not much difference in CRL obtained by TAS and TVS in our study. The mean of the CRL obtained by either procedures was found to be almost same.

\section{Diagnostic breakdown of cases}

Combining the clinical and ultrasonographic findings, diagnosis was made for the cases.

Guidelines for transvaginal ultrasonographic diagnosis of pregnancy failure in a woman with an intrauterine pregnancy of uncertain viability:

\section{Findings suspicious for, but not diagnostic of pregnancy} failure:

1) Crown rump length of less than $7 \mathrm{~mm}$ and no heartbeat. 2) Mean sac diameter of 16-24 $\mathrm{mm}$ and no embryo. 3) Absence of embryo with heartbeat 7-13 days after a scan that showed a gestational sac without a yolk sac. 4) Absence of embryo with heartbeat 7-10 days after a scan that showed a gestational sac with a yolk sac. 5) Absence of embryo for 6 weeks or longer after last menstrual period. 6) Empty amnion (amnion seen adjacent to yolk sac with no visible embryo). 7) Enlarged yolk sac (greater than $7 \mathrm{~mm}$ ). 8) Small gestational sac in relation to the size of the embryo (less than $5 \mathrm{~mm}$ difference between mean sac diameter and crown rump length).

\section{Findings diagnostic of pregnancy failure}

1) Crown rump length of $7 \mathrm{~mm}$ or greater and no heartbeat. 2) Mean sac diameter of $25 \mathrm{~mm}$ or greater and no embryo. 3) Absence of embryo with heartbeat 2 weeks or more after a scan that showed a gestational sac without a yolk sac. 4) Absence of embryo with heartbeat 11 days or more after a scan that showed a gestational sac with a yolk sac. ${ }^{9}$

\section{Incomplete abortion}

a) Uterine size smaller than the period of amenorrhoea. b) Cavity filled up with products of conceptions which gave echoes of amorphous masses of different sizes and shapes and echogenecity representing placental tissue, blood clots etc. Process of miscarriage progressed to an irreversible stage. ${ }^{10}$

\section{Missed abortion}

a) Demonstrable fetus. b) Absence of heart activity. c) Discrepancy of size between fetus and gestational sac. ${ }^{10}$ 


\section{Blighted ovum}

For TAS, a gestational sac diameter of $20 \mathrm{~mm}$ without a yolk sac or $25 \mathrm{~mm}$ without a fetus was taken as a criteria of blighted ovum. ${ }^{11}$

For TVS the corresponding figures were 10 and $18 \mathrm{~mm}$, respectively. ${ }^{12}$

Threatened abortion was mainly diagnosed clinically as there were no specific ultrasonographic findings but the patient presented with suggestive complaints.

Table 8: Diagnostic breakdown of cases.

\begin{tabular}{|lll|}
\hline Pregnancy & Cases & Percentage \\
\hline Normal & 56 & 70 \\
\hline Abnormal & 24 & 30 \\
\hline Abnormal & & \\
\hline Incomplete abortion & 09 & 37.5 \\
\hline Threatened abortion & 08 & 33.33 \\
\hline Missed abortion & 05 & 20.83 \\
\hline Blighted ovum & 02 & 8.33 \\
\hline Total & 24 & 100 \\
\hline
\end{tabular}

\section{DISCUSSION}

In this study, measurement of mean sac diameter and crown rump length at corresponding gestational age by transvaginal and abdominal sonography were found to be identical. Kaur et al by their similar study, found the mean sac diameter and crown rump length measured by transvaginal and abdominal sonography in early pregnancy to be almost identical. ${ }^{8}$

This was found similar to our study.

In this study gestational sac was detected in better percentage of cases of normal pregnancy by TVS $(100 \%)$ than by TAS $(92.16 \%)$. Abnormality in gestational sac in cases of abnormal pregnancy was better detected by TVS $(60 \%)$ than by TAS $(40 \%)$.

In the study conducted by Kaur et al, TVS detected regular shape of gestational sac in more number of cases compared with TAS and also detected abnormality in more number of cases than that detected by TAS. They concluded that abnormal shape of gestation sac is diagnostic of abnormal pregnancy and is $100 \%$ specific in the case of TVS, whereas this cannot be said about TAS, where over distended urinary bladder may distort even the normal gestation sac. ${ }^{8}$

TVS is more efficient in assessing the presence of gestational sac in early first trimester of pregnancy rather than the TAS.
Mahmoud et al with their study concluded that TVS is more efficient in assessing the presence of gestational sac in early first trimester of pregnancy rather than TAS. ${ }^{13}$

Yolk sac was detected better by TVS $(97.87 \%)$ than by TAS $(95.35 \%)$ in cases of normal pregnancy in this study. TVS $(72.73 \%)$ could also detect abnormality in yolk sac better than TAS $(36.36 \%)$ amongst cases of abnormal pregnancy.

Double decidual sac sign was detected by transvaginal sonography $(92.31 \%)$ in more percentage of cases than by transabdominal sonography $(46.15 \%)$ in this study.

Fetal pole was visualised in more number of cases by TVS $(95.74 \%)$ than by TAS $(93.02 \%)$. Fetal heart motion was evident in $93.33 \%$ of cases as detected by TVS compared to $87.5 \%$ cases detected by TAS. Study conducted by Rani et al concluded that transvaginal sonography (TVS) was more sensitive to visualise foetal pole, yolk sac and cardiac activity compared to transabdominal sonography (TAS). Yolk sac was visualised in more number of cases by TVS, than that detected by TAS. ${ }^{14}$

Kaur et al concluded that TVS showed additional information in more patients as compared to TAS, in detection of gestation sac, yolk sac or better visualization of embryonic anatomy. In the abnormal pregnancy TVS provided more information in 11 cases $(64.9 \%)$, which included detection of embryonic demise or yolk sac. ${ }^{8}$

These findings were found similar to our study.

Limitations seen with transvaginal sonography are limited movability of the probe, field of view was limited and the need for proper counselling to the patient before the procedure.

\section{CONCLUSION}

To conclude it can be said that transvaginal sonography provides better information and better image quality than abdominal sonography, and also helps in identifying various early developmental markers and their abnormalities, thus contributing to better diagnosis of early pregnancy failure. Transvaginal sonography reveals additional information in a greater proportion of cases as compared to transabdominal sonography thus helping to identify early pregnancy failure with more accuracy. Through this study we can conclude that at times, relying solely on transvaginal sonography may not be advisable, as the combination of transabdominal sonography and vaginal sonography complements the defects of two methods and thus improves the accuracy of diagnosis. Thus it can be said that transvaginal sonography should not be used as a substitute but as a conjunct with transabdominal sonography for better visualisation and improved diagnosis thereby helping in better management of the patients. 
Funding: No funding sources

Conflict of interest: None declared

Ethical approval: The study was approved by the Institutional Ethics Committee

\section{REFERENCES}

1. American College of Obstetricians and Gynecologists. Early pregnancy loss. Practice Bulletin No. 150. Obstet Gynecol 2015;125:1258-67.

2. Wilcox AJ, Weinberg CR, O'Connor JF, Baird DD, Schlatterer JP, Canfield RE, Armstrong EG, Nisula BC. Incidence of early loss of pregnancy. N Engl J Med. 1988;319(4):189-94.

3. Wilcox AJ, Weinberg CR, O'Connor JF, Baird DD, Schlatterer JP, Canfield RE, et al. Conception, early pregnancy loss, and time to clinical pregnancy: a population-based prospective study. Fertil Steril. 2003;79:577-84.

4. Hill LM, Guzick D, Fries J, Hixson J. Fetal loss rate after ultrasonically documented cardiac activity between 6 and 14 weeks, menstrual age. J Clin Ultrasound. 1991;19(4):221-3.

5. Wyatt PR, Owolabi T, Meier C, Huang T. Agespecific risk of fetal loss observed in a second trimester serum screening population. Am J Obstet Gynecol. 2005;192(1):240-6.

6. athi RB, Milki, A. Tissue sampling technique affects accuracy of karyotype from missed abortions. J Assist Reprod Genet. 2002;19:536-8.

7. Morin L, Cargill YM, Glanc P. Ultrasound evaluation of first trimester complications of pregnancy. J Obstet Gynaecol Canada. 2016;38(10):982-8.
8. Kaur A, Kaur A. Transvaginal ultrasonography in first trimester of pregnancy and its comparison with transabdominal ultrasonography. J Pharm Bioallied Sci. 2011;3(3):329-38.

9. Doubilet PM, Benson CB, Bourne T, Blaivas M. Diagnostic criteria for non viable pregnancy early in the first trimester. Society of Radiologists in Ultrasound Multispeciality Panel on Early First trimester diagnosis of miscarriage and exclusion of a viable intrauterine pregnancy. $\mathrm{N}$ Engl $\mathrm{J}$ Med 2013;369:1443-51.

10. Arias F, Bhide AG, Arulkumaran S, Damania K, Daftary SN, editors. Practical Guide to High Risk Pregnancy and Delivery. 4th edn. Elsevier health sciences; 2012;107-108.

11. Nyberg DA, Laing FC, Filly RA. Threatened abortion: sonographic distinction of normal and abnormal gestation sacs. Radiology. 1986;158:397400.

12. Nyberg DA, Hill LM. Normal early intrauterine pregnancy: Sonographic development and HCG correlation. In: Nyberg DA, Hill LM, Bohm-Velez M, Mendelson EB, eds. Transvaginal Ultrasound. St. Louis: Mosby-Year Book; 1992:65.

13. Mustafa MZ. Transvaginal scan versus transabdominal scan for gestational sac detection in the early first trimester of pregnancy in Sudanese ladies. Asian J Med Clin Sci. 2012;1:19-21.

14. Rani PR, Sunita V. Ultrasound evaluation of vaginal bleeding in first trimester of pregnancy. J Ostet Gynecol Ind. 2000;50:54-8.

Cite this article as: Khanam R, Nath P. Role of transvaginal sonography in the diagnosis of early pregnancy failure. Int J Reprod Contracept Obstet Gynecol 2021;10:662-8. 